\title{
Correlation between Dental Hygiene Student's Gender Sensitivity and Gender Role Stereotypes
}

\author{
$\mathrm{Ji}-$ Min Hwang ${ }^{1}$ and Ji-Hyoung $\mathrm{Han}^{2, \dagger}$ \\ 'Department of Dental Hygiene, Baekseok Culture University, Cheonan 31065, ${ }^{2}$ Department of Dental Hygiene, \\ Suwon Science College, Hwaseong 18516, Korea
}

\begin{abstract}
Background: The purpose of this study is to identify the gender sensitivity and gender role stereotypes of students in dental hygiene and to provide basic data to expand social awareness of equal gender sensitivity and gender role in dental hygiene and students by identifying the degree of correlation.

Methods: The purpose of this study was to study dental hygiene students at colleges in Gyeonggi and Chungcheong areas. The survey was conducted from April 1 to April 30, 2021. The final sample was analyzed on 157 subjects. T-test and ANOVA analysis were performed to compare gender sensitivity and gender role stereotypes according to general characteristics. Equal variances were tested using the Levene statistic, and significant differences between groups were identified through Scheffe's post hoc analysis. Pearson's correlation analysis was performed to confirm the correlation between gender sensitivity and gender role stereotypes.

Results: Gender sensitivity was 2.69 and gender role stereotypes were 1.83. Among the sub-areas of gender sensitivity, gender role openness was the highest at 2.86, and non-violence was the lowest at 2.50. As for gender role stereotypes, social stereotypes were the highest among sub-areas at 1.71. Among the general characteristics, there was a statistically significant difference in gender sensitivity according to the presence or absence of opposite sex friends $(p=0.011)$. The gender identity openness of gender sensitivity and the physical sub-areas of gender role stereotypes showed the highest positive correlation $(r=0.955)$. Among the sub-areas of gender sensitivity, gender role openness and domestic stereotypes showed the lowest negative correlation ( $r=-0.404)$ among the sub-areas of gender role stereotypes.

Conclusion: Dental hygiene students should be able to critically analyze and solve problems of not only sexual violence but also gender discrimination and imbalance in social life. For this, environmental factors such as school education and professor guidance must be strengthened.
\end{abstract}

Key Words: Dental hygiene, Gender role stereotypes, Gender sensitivity

\section{Introduction}

According to the Global gender gap report 2021, Korea's gender gap index rank was 102 nd out of 156 countries in the world ${ }^{1)}$. Gender refers to the psychological, social, and cultural gender differences between men and women, unlike the concept of physical and biological sex. In other words, it approaches gender as a social structural dimension ${ }^{2}$. The gender gap in Korean society begins with an old perception. Traditionally, women are in charge of childbirth, child rearing, and housework, while men are considered to be in charge of economic activities in society. This made women dependent on men and consequently affected the decline of status ${ }^{3)}$. In addition, women with relatively weak bodies are more exposed to sexual violence crimes, such as sexual harassment, molestation, and sexual assault, than men, and misogyny crimes also occur, exacerbating gender conflict. These social phenomena are related to gender sensitivity and gender role stereotypes. Gender sensitivity is the ability to detect gender-related 
problems. It means the will to practice and the ability to act to understand and improve the effects of gender issues and gender discrimination and inequality arising from gender role stereotypes in everyday life ${ }^{3,4)}$. Gender role stereotypes relate personal attributes to social categories of masculinity and femininity. In other words, behaviors and attitudes are classified according to gender, and personality, values, behaviors, and verbal expressions are classified as man or woman ${ }^{5,6)}$. However, in recent years, the notion of gender role that has been fixed in advanced countries is changing.

In Korea, too, the concept and culture of gender are changing, and in particular, there have been many changes in the sexual attitudes and behaviors of college students who begin their sexual experience. Awareness and conception of gender roles of college students are important in establishing gender identity and forming social relationships $^{3)}$. Therefore, many studies have investigated gender sensitivity and gender role stereotypes targeting university students $^{4,7-10)}$. Dental hygiene students work in dentistry after graduation and face a variety of colleagues and patients. At this time, various conflicts about gender sensitivity and gender role stereotypes can arise. Therefore, it is necessary to have a proper understanding and awareness of it. The purpose of this study was to identify the gender sensitivity and gender role stereotypes of dental hygiene students and to determine the degree of correlation. In addition, it is intended to provide basic data to expand social awareness of dental hygiene and students equal gender sensitivity and gender role.

\section{Materials and Methods}

\section{Subjects}

The data for this study were selected from convenience samples from students enrolled in the Department of Dental Hygiene of colleges in Gyeonggi and Chungcheong regions. The survey period was from April 1 to April 30, 2021. In order to comply with research ethics, the research was conducted with the consent of the subjects. As for the sample size, more than 138 people were calculated based on the significance level of 0.05 , statistical power of 0.95 , and effect size of 0.3 required for correlation using the $G$
Power 3.1 program. The final sample was analyzed in 157 subjects.

\section{Variables used in the analysis}

For general characteristics, a total of 8 items were investigated: gender, grade, economic level, residence, family type, presence of friends of the opposite sex, education experience related to gender sensitivity, and education experience related to gender role stereotypes. For the gender sensitivity variable, the tool developed by Lee $^{11)}$ was used. Gender role openness (9 questions), gender identity openness (7 questions), non-violence (7 questions), and introspection (8 questions) were classified into 4 sub-areas and 31 questions. This is a Likert 4-point scale response method, consisting of responses such as 'strongly disagree' (1 point) and 'strongly agree' (4 points), with higher scores indicating higher gender sensitivity. Cronbach's $\alpha$ value was 0.846 . The gender role stereotype variable was developed by $\mathrm{Kim}^{12}$ and modified and supplemented by $\operatorname{Han}^{13)}$. The final tool consisted of a total of 26 items with 5 sub-areas. The five sub-areas are domestic (6 questions), social (5 questions), physical (4 questions), socio-psychological (6 questions), and cognitive (5 questions). Each questions was constructed in a Likert 4-point scale response method, with responses 'strongly disagree' (1 point) and 'strongly agree' (4 points). Higher scores indicate higher gender role stereotypes. Cronbach's $\alpha$ value was 0.862 .

\section{Data analysis}

Descriptive statistics were analyzed to confirm the gender sensitivity and gender role stereotypes. T-test and ANOVA analysis were performed to compare gender sensitivity and gender role stereotypes according to general characteristics. Equal variances were tested using the Levene statistic, and significant differences between groups were identified through Scheffe's post hoc analysis. Pearson's correlation analysis was performed to confirm the correlation between gender sensitivity and gender role stereotypes. Data were analyzed using SPSS Statistics 12.0 (SPS Inc., Chicago, IL, USA). The significance level of all statistical analyzes was 0.05 . 


\section{Results}

\section{Gender sensitivity and gender role stereotypes}

Gender sensitivity was 2.69 and gender role stereotypes were 1.83. Among the sub-areas of gender sensitivity, gender

Table 1. Gender Sensitivity and Gender Role Stereotypes

\begin{tabular}{lc}
\hline \multicolumn{1}{c}{ Variable } & Value \\
\hline Gender sensitivity & $2.69 \pm 0.338$ \\
Gender role openness & $2.86 \pm 0.372$ \\
Gender identity openness & $2.85 \pm 0.624$ \\
Non-violence & $2.50 \pm 0.429$ \\
Introspection & $2.53 \pm 0.466$ \\
Gender role stereotypes & $1.83 \pm 0.262$ \\
Domestic & $1.46 \pm 0.421$ \\
Social & $1.71 \pm 0.313$ \\
Physical & $1.63 \pm 0.501$ \\
Socio-psychological & $1.63 \pm 0.501$ \\
Cognitive & $1.52 \pm 0.504$ \\
\hline
\end{tabular}

Values are presented as mean \pm standard deviation. role openness was the highest at 2.86, and non-violence was the lowest at 2.50. As for gender role stereotypes, among the sub-areas, social stereotypes were the highest at 1.71 and domestic stereotypes were the lowest at 1.46 (Table 1).

\section{Gender sensitivity and gender role stereotypes according to general characteristics}

Among the general characteristics, there was a statistically significant difference in gender sensitivity according to the presence or absence of opposite sex friends $(p=0.011)$. It was 2.61 when a friend of the opposite sex was present, and 2.74 when a friend of the opposite sex was not present, indicating that the more there were friends of the opposite sex, the lower the sensitivity to gender (Table 2).

Table 2. Gender Sensitivity and Gender Role Stereotypes according to General Characteristics

\begin{tabular}{|c|c|c|c|c|c|c|c|c|}
\hline \multirow[b]{2}{*}{ Characteristic } & \multirow[b]{2}{*}{ Category } & \multirow[b]{2}{*}{$\mathrm{n}(\%)$} & \multicolumn{3}{|c|}{ Gender sensitivity } & \multicolumn{3}{|c|}{ Gender role stereotypes } \\
\hline & & & $\begin{array}{l}\text { Mean } \pm \text { standard } \\
\text { deviation }\end{array}$ & $\mathrm{t} / \mathrm{F}$ & Scheffe & $\begin{array}{l}\text { Mean } \pm \text { standard } \\
\text { deviation }\end{array}$ & $\mathrm{t} / \mathrm{F}$ & Scheffe \\
\hline \multirow[t]{3}{*}{ Grade } & $1^{\mathrm{a}}$ & $50(31.8)$ & $2.74 \pm 0.316$ & 0.969 & $\mathrm{n} / \mathrm{a}$ & $1.85 \pm 0.281$ & 0.287 & $\mathrm{n} / \mathrm{a}$ \\
\hline & $2^{\mathrm{b}}$ & $51(32.5)$ & $2.68 \pm 0.329$ & & & $1.83 \pm 0.258$ & & \\
\hline & $3^{c}$ & $56(35.7)$ & $2.64 \pm 0.365$ & & & $1.81 \pm 0.253$ & & \\
\hline \multirow[t]{3}{*}{ Economic level } & Top $^{\mathrm{a}}$ & $19(12.1)$ & $2.77 \pm 0.236$ & 0.063 & $\mathrm{a}<\mathrm{c}$ & $1.89 \pm 0.258$ & 0.746 & $\mathrm{n} / \mathrm{a}$ \\
\hline & Middle ${ }^{\mathrm{b}}$ & $132(84.1)$ & $2.69 \pm 0.347$ & & & $1.82 \pm 0.265$ & & \\
\hline & Bottom $^{c}$ & $6(3.8)$ & $2.40 \pm 0.312$ & & & $1.75 \pm 0.224$ & & \\
\hline \multirow[t]{3}{*}{ Residence } & Seoul $^{\mathrm{a}}$ & $20(12.7)$ & $2.63 \pm 0.307$ & 3.031 & $\mathrm{a}<\mathrm{c}$ & $1.88 \pm 0.261$ & 1.066 & $\mathrm{n} / \mathrm{a}$ \\
\hline & Incheon, Gyeonggi ${ }^{b}$ & $116(73.9)$ & $2.67 \pm 0.344$ & & & $1.81 \pm 0.263$ & & \\
\hline & Chungcheong $^{\mathrm{c}}$ & $21(13.4)$ & $2.85 \pm 0.294$ & & & $1.89 \pm 0.259$ & & \\
\hline \multirow[t]{4}{*}{ Family type } & Parents $^{\mathrm{a}}$ & $143(91.1)$ & $2.69 \pm 0.342$ & 0.616 & $\mathrm{n} / \mathrm{a}$ & $1.83 \pm 0.261$ & 1.446 & $\mathrm{n} / \mathrm{a}$ \\
\hline & Single mother ${ }^{\mathrm{b}}$ & $6(3.8)$ & $2.78 \pm 0.323$ & & & $1.96 \pm 0.254$ & & \\
\hline & Single father ${ }^{c}$ & $2(1.3)$ & $2.65 \pm 0.370$ & & & $1.54 \pm 0.129$ & & \\
\hline & $\mathrm{Etc}^{\mathrm{d}}$ & $6(3.8)$ & $2.53 \pm 0.278$ & & & $1.77 \pm 0.300$ & & \\
\hline \multirow[t]{2}{*}{ Opposite sex friend } & Yes & $63(40.1)$ & $2.61 \pm 0.282$ & $-2.581^{*}$ & & $1.84 \pm 0.263$ & 0.484 & \\
\hline & No & $94(59.9)$ & $2.74 \pm 0.363$ & & & $1.82 \pm 0.263$ & & \\
\hline \multirow{2}{*}{$\begin{array}{l}\text { Education experience } \\
\text { related to gender } \\
\text { sensitivity }\end{array}$} & Yes & $35(22.3)$ & $2.75 \pm 0.380$ & 1.286 & & $1.78 \pm 0.262$ & -1.159 & \\
\hline & No & $122(77.7)$ & $2.67 \pm 0.325$ & & & $1.84 \pm 0.262$ & & \\
\hline \multirow{2}{*}{$\begin{array}{l}\text { Education experience } \\
\text { related to gender role } \\
\text { stereotypes }\end{array}$} & Yes & $66(42.0)$ & $2.72 \pm 0.364$ & 1.053 & & $1.81 \pm 0.251$ & -0.956 & \\
\hline & No & $91(58.0)$ & $2.66 \pm 0.318$ & & & $1.85 \pm 0.270$ & & \\
\hline
\end{tabular}

n/a: not available.

${ }^{\mathrm{a} \sim \mathrm{d}}$ Data was analyzed by t-test and one-way ANOVA statistics.

$* \mathrm{p}<0.05$. 


\section{Correlation between gender sensitivity and sub-areas of gender role stereotypes}

The gender identity openness of gender sensitivity and the physical sub-areas of gender role stereotypes showed the highest positive correlation $(\mathrm{r}=0.955)$. Among the sub-areas of gender sensitivity, gender role openness and domestic stereotypes showed the lowest negative correlation $(\mathrm{r}=-0.404)$ among the sub-areas of gender role stereotypes (Table 3).

\section{Correlation between gender sensitivity and gender role stereotypes}

There was no statistically significant difference in the correlation between gender sensitivity and gender role stereotypes (Table 4).

\section{Discussion}

This study tried to identify the gender sensitivity and gender role stereotypes of dental hygiene students and to determine the degree of their correlation, and the discussion according to the study results is as follows.

The average gender sensitivity of dental hygiene students was 2.69. The study result of Joo et al. ${ }^{7)}$ for university students was 3.20, and the result of Yang et al. ${ }^{4)}$ for nursing students was 2.99, which was lower in this study. Among the sub-area of gender sensitivity, openness to gender roles and gender identity openness were high. In the study of Lim et al. ${ }^{9)}$ which targeted dental hygiene students, gender role openness was also the highest score. The dental hygiene students did not discriminate with respect to gender roles, and the ability to respect various differences in gender identity without prejudice and accept them with an open mind was high. Among the sub-domains of gender sensitivity, non-violence was the lowest at 2.50, and the ability to recognize not only physical violence but also absurdity and injustice as violence is low, so it is necessary to supplement this. As a result of the study, the gender role stereotypes were 1.83 . The result of Cho et al. ${ }^{10)}$, which investigated male nursing students, was 2.58 , which supported the result of Han et al. ${ }^{5)}$ that women showed more gender-equal attitudes than men. The score for each sub-area was lowest for social stereotypes at 1.71 and for domestic stereotypes at 1.46. The biggest reason for applying to the Department of Dental Hygiene is that dental hygienists are professional and have a high employment rate. This perception seems to have been

Table 4. Correlation between Gender Sensitivity and Gender Role Stereotypes

\begin{tabular}{lcc}
\hline \multicolumn{1}{c}{ Variable } & $\begin{array}{c}\text { Gender } \\
\text { sensitivity }\end{array}$ & $\begin{array}{c}\text { Gender role } \\
\text { stereotypes }\end{array}$ \\
\hline Gender sensitivity & 1 & \\
Gender role stereotypes & 0.453 & 1 \\
\hline
\end{tabular}

Table 3. Correlation between Gender Sensitivity and Sub-Areas of Gender Role Stereotypes

\begin{tabular}{|c|c|c|c|c|c|c|c|c|c|}
\hline Variable & $\begin{array}{c}\text { Gender role } \\
\text { openness }\end{array}$ & $\begin{array}{c}\text { Gender } \\
\text { identity } \\
\text { openness }\end{array}$ & $\begin{array}{c}\text { Non- } \\
\text { violence }\end{array}$ & Introspection & Domestic & Social & Physical & $\begin{array}{c}\text { Socio- } \\
\text { psychological }\end{array}$ & Cognitive \\
\hline $\begin{array}{l}\text { Gender role } \\
\text { openness }\end{array}$ & 1 & & & & & & & & \\
\hline $\begin{array}{l}\text { Gender identity } \\
\text { openness }\end{array}$ & $0.515 * * *$ & 1 & & & & & & & \\
\hline Non-violence & $0.250 * *$ & $0.209^{* *}$ & 1 & & & & & & \\
\hline Introspection & $0.493 * * *$ & $0.407 * * *$ & 0.154 & 1 & & & & & \\
\hline Domestic & $-0.404 * * *$ & $-0.347 * * *$ & $-0.163 *$ & $-0.214 * *$ & 1 & & & & \\
\hline Social & $-0.217 * *$ & $-0.201 *$ & 0.154 & -0.100 & $0.349 * * *$ & 1 & & & \\
\hline Physical & $0.458 * * *$ & $0.955 * * *$ & 0.142 & $0.369 * * *$ & $-0.318^{* * *}$ & $-0.193 *$ & 1 & & \\
\hline $\begin{array}{l}\text { Socio- } \\
\text { psychological }\end{array}$ & $-0.223^{* *}$ & $-0.233 * *$ & -0.120 & -0.021 & $0.580 * * *$ & $0.259 * *$ & $-0.253^{* *}$ & 1 & \\
\hline Cognitive & $-0.252 * *$ & $-0.286^{* * *}$ & -0.134 & -0.074 & $0.532 * * *$ & $0.306^{* * *}$ & $-0.295 * * *$ & $0.719 * * *$ & 1 \\
\hline
\end{tabular}

Data was analyzed by Pearson correlation statistics.

${ }^{*} \mathrm{p}<0.05,{ }^{* *} \mathrm{p}<0.01,{ }^{* * *} \mathrm{p}<0.001$. 
positively expressed in women's decision-making rights, political status, and women's advancement into society.

Among general characteristics, gender sensitivity differed according to the presence of heterosexual friends, grade, and economic level. In the study of Joo et al. ${ }^{7)}$, there was no significant difference according to the experience of heterosexual dating, but there was a significant difference in gender and age. The higher the grade and the lower the economic level, the lower the gender sensitivity. It can be inferred that the younger the population and the more economical they are, the more they perceive stereotypes and prejudices about gender, and the higher their will to realize a gender-equal society.

It is reported that gender sensitivity is changed based on understanding of a gendered society and empathy with others while having sensitivity to differences and discrimination from others ${ }^{3)}$. Gender sensitivity should be changed based on understanding of individual life together regardless of gender. Dental hygienists, who are mostly female, should detect gender discrimination and inequality in gender role stereotypes in clinical practice, and try to correct irrational situations. In the study of Han et al. ${ }^{5)}$, as for gender role stereotypes, the older the age, the more conservative thinking was maintained by males than females, married people rather than single people, and low-educated people rather than high-educated people. Korea, which has been very conservative and closed in the past, still lacks understanding and change in gender sensitivity and gender role stereotypes, as shown in the gender gap index. These two are formed as a single value by being influenced by parents and society from an early age. And that value lasts a lifetime and is passed on to future generations. Looking at the correlation between gender sensitivity and gender role stereotypes, among the sub-area of gender sensitivity, gender role openness and gender identity openness were highly correlated with physical and social characteristics, sub-area of gender role stereotypes. That is, the open perception of gender identity such as gender roles and homosexuality, regardless of gender, was highly related to stereotypes of women's appearance and social status. Everyone has a different way of thinking. Therefore, high gender role stereotypes cannot be said to be bad. However, the more traditionally the gender role stereotypes are recognized, the lower the awareness of gender equality ${ }^{6}$ ) will cause conflict between the old generation and the new generation in dental medical institutions.

This conflict is related to the turnover rate of dental hygienists. Communication is necessary above all else to reduce generational conflict between co-workers working at dental medical institutions. Since gender sensitivity is related to gender role stereotypes, it will be possible to resolve conflicts and reduce the turnover rate by implementing a program on gender sensitivity for each institution.

This study has limitations in generalizing it to dental hygiene students at some colleges. In addition, this study was sexually related, and although gender comparison is important, only female students were targeted due to the structural characteristics of the gender ratio with dental hygiene. A comparative study involving male students is needed in the future, although it is a small number. Unlike in the past, gender sensitivity and gender role stereotypes are changing a lot due to the improvement of women's educational level and the expansion of social advancement. In particular, most dental hygiene students work in dental hospitals or related institutions after graduation. When faced with various types of discrimination and imbalances in social life, it is necessary to critically analyze them and to find alternatives to solve them. Thinking about gender roles can be reinforced by environmental factors. It can be strengthened or mitigated under the influence of school education, university colleagues, and advisors. Therefore, in order to raise the awareness of gender equality, it is necessary to strengthen the school education and provide interest in dental hygiene students regarding gender sensitivity and gender role stereotypes.

\section{Notes}

\section{Conflict of interest}

No potential conflict of interest relevant to this article was reported. 


\section{Ethical approval}

This study was approved by the Institutional Review Board of Baekseok Culture University (No.2-70087132A-N-01).

\section{Author contributions}

Conceptualization: Ji-Min Hwang and Ji-Hyoung Han. Data acquisition: Ji-Min Hwang. Formal analysis: Ji-Min Hwang. Supervision: Ji-Hyoung Han. Writing-original draft: Ji-Min Hwang and Ji-Hyoung Han. Writing - review \& editing: Ji-Hyoung Han and Ji-Min Hwang.

\section{ORCID}

Ji-Min Hwang, https://orcid.org/0000-0003-2199-8319

Ji-Hyoung Han, https://orcid.org/0000-0003-1613-2879

\section{References}

1. Retrieved August 9, 2021, from https://www3.weforum.org/ docs/WEF_GGGR_2021.pdf(2021).

2. Yun GH, Yang MS, Jang IS: Analysis of gender sensitivity, gender equality policy recognition and satisfaction according to demographic sociological characteristics of police officials. PSJ 14: 9-37, 2019. https://doi.org/10.16961/polips.2019.14.4.9

3. Shin NR, Shin JY, Han SM: A study on processes of change in gender sensitivity: college students' group counseling experiences. KALCI 21: 1363-1384, 2021. https://doi.org/10.22251/jlcci.2021.21.3.1363

4. Yang YM, Cho MO, Baek KH: The effects of sexual attitude and sexual knowledge of nursing students on gender sensitivity. JCIT 11: 55-63, 2021. https://doi.org/10.22156/CS4SMB.2021.11.06.055

5. Han JH, Huh MY, Park JH: The influence of gender-role stereotypes on dating violence - focusing on the mediating effect of violence tolerance -. Korean J Saf Cult 12: 125-143, 2021.

https://doi.org/10.52902/kjsc.2021.12.125

6. Ah YA: The effects of gender role stereotypes of parents as perceived by adolescents on the gender sensitivity of adolescents and the moderating effect of human rights consciousness. $\mathrm{J}$ Sch Soc Work 51: 79-98, 2020. https://doi.org/10.20993/jSSW.51.4

7. Joo KS, Kim KM, Lee JP: A study on the effect of sociality and self-esteem of college students on gender sensitivity. KALCI 20: 213-229, 2020. https://doi.org/10.22251/jlcci.2020.20.6.213

8. Kim SH, Leem GH, Sung HJ, et al.: The influence of undergraduate students' gender sensitivity on the perception of sexual violence in positions of power imbalance. KPSR 18: 3-36, 2019. https://doi.org/10.38084/2019.18.4.1

9. Lim HJ, Kim KE, NamKoong EJ: Gender sensitivity and gender equality consciousness of dental hygiene students. J Dent Hyg Sci 21: 111-118, 2021. https://doi.org/10.17135/jdhs.2021.21.2.111

10. Cho SH, Kwon SH, Rho IS: Relationship among perceived male friendliness nursing programs, gender role stereotype, and major satisfaction in Korean male nursing students. Stress 28: 213-220, 2020. https://doi.org/10.17547/kjsr.2020.28.4.213

11. Lee JY: A study on developing gender sensitivity measurement. Unpublished master's thesis, Ewha Womans University, Seoul, 2010.

12. Kim DI: A study on the relationship between gender stereotypes and authoritarianism. Korea Cult Res Inst 63: 45-58, 1993.

13. Han JH: A study on gender-role stereotypes and dating violence. Unpublished doctoral dissertation, Kongju National University, Gongju, 2020. 